
\title{
25 Research Square \\ Using Chiral Magnetic Surface Molecularly Imprinted Polymers for Chiral Separation of Ofloxacin
}

\section{ZHAO CHEN ( $\sim 19379886 @ q q . c o m)$}

xi'an techological university

\section{Wenzong Lu}

Xi'an technological University

\section{Mengxiang Yang \\ Xi'an technological University}

\section{Research}

Keywords: surface molecularly imprinted polymer; chiral reagent; magnetic particles; ofloxacin

Posted Date: August 11th, 2020

DOI: https://doi.org/10.21203/rs.3.rs-48861/v1

License: (c) (i) This work is licensed under a Creative Commons Attribution 4.0 International License.

Read Full License 


\section{Abstract}

\section{Background}

Ofloxacin is an important drug with anti-bacterial effects, and (-)-ofloxacin has been shown to have better anti-bacterial activity than racemic ofloxacin. But chiral resolution of compounds is a major challenge worldwide. Many methods do not show high specificity to target molecules, causing errors in the separation of these pharmaceutical molecules, thus affecting the purity of drugs.

\section{Method}

The paper mainly research on a method for quick resolution of ofloxacin using chiral magnetic surface molecular imprinting polymers (chiral MMIP). $\mathrm{Fe}_{3} \mathrm{O}_{4}$ magnetic nanoparticles coated with silica is acted as the substrate. Chiral reagent is $\mathrm{N}$-octyl-D-glucosamine as monomer, with ofloxacin as the template molecules to prepare magnetic surface molecularly imprinted polymer. The chiral polymer can be combined with (+)-ofloxacin, eventually (-)-ofloxacin was isolated.

\section{Results}

Finally by using extermal magnetic field and transmission electron microscopy (TEM), the character of magnetic surface molecularly imprinted polymer is tested, and The product was tested by ultraviolet spectrum and optical rotation tests and was confirmed to be (-)-ofloxacin.

\section{Conclusion}

A simple, rapid, and cost-effective method for separating chiral compounds was established.

\section{Background}

Ofloxacin(a racemic drug) is a white crystalline powder $[$ odorless $\square$ bitter and easy to change color when exposed to light. It has strong antibacterial effect and can inhibit most bacteria[1-3]. The antibacterial effect of (-)-ofloxacin on Gram-negative and positive bacteria was 8-128 times higher than that of (+)ofloxacin. (-)-ofloxacin can inhibit the activity of bacterial DNA gyrase, thus prevent the synthesis and replication of bacterial DNA, resulting in the rapid death of bacteria. The structural formula is shown in Fig. 1. Asymmetric synthesis is usually used to prepare (-)-ofloxacin. Although the optical purity of (-)ofloxacin can be directly obtained by asymmetric synthesis, the yield of optically pure material prepared by this method is generally low. If appropriate chiral separation technology is used, the corresponding isomers with high yield can be obtained[4-5].

Chiral resolution of compounds is a major challenge worldwide. Although various methods for chiral resolution, such as gas chromatography (GC)[6], high performance liquid chromatography (HPLC)[7-8], and capillary electrophoresis(CE)[9-10], exist, these methods do not show high specificity to target molecules, causing errors in the separation of these pharmaceutical molecules, thus affecting the purity 
of drugs. GC is a relatively new technique for separation and analysis of compounds, and is widely used in industry, agriculture, defense, construction, and scientific research. HPLC, although more precise, is disadvantaged in that samples require a complex and cumbersome pre-processing. In addition, HPLC is a time-consuming and expensive technique unsuitable for rapid detection. Therefore, effective, simple, and rapid resolution methods need to be developed. Magnetic molecularly imprinted polymers (MMIPs) could represent a solution to this problem[11-12]. MMIPs are generated by combining magnetic materials with molecularly imprinted polymers (MIPs)[13-14]. Application of an external magnetic field results in the rapid separation of MMIPs. MMIPs are known to be capable of actively distinguishing and rapidly separating template molecules[15-16]. Iron (II, III) oxide, $\mathrm{Fe}_{3} \mathrm{O}_{4}$, is the most widely used magnetic material due to its low toxicity, low cost, and high stability[17-18].

The use of MMIPs for chiral resolution satisfies the need for rapid detection, is highly sensitive, has low cost, and has the potential for a wide range of applications. For preparing MMIPs, a chiral reagent is used as a monomer, while racemic drugs are used as template molecules, thus solving the problem of obtaining pure enantiomers for use as templates during chiral separation. The MMIP technology could overcome challenges that occur during the binding and elution of template molecules and MMIPs, as well as the problem of low number of sites for MMIP binding[19-20].

The aim of this study was to achieve the quick resolution of ofloxacin using MMIP technology.

\section{Results}

Infrared spectroscopic analysis of ofloxacin chiral MMIPs

The standard wave number of $\mathrm{Fe}_{3} \mathrm{O}_{4}$ is $580 \mathrm{~cm}^{-1}$. Figure 2(a) shows a wide and strong absorbance peak at $561 \mathrm{~cm}^{-1}$ in the infrared spectrum of $\mathrm{Fe}_{3} \mathrm{O}_{4}$. This was likely because of a "purple shift" in the $\mathrm{Fe}_{3} \mathrm{O}_{4}$ infrared spectrum, caused because the dimensions of the $\mathrm{Fe}_{3} \mathrm{O}_{4}$ crystals produced were in the nanoscale. Figure 2(b) shows a strong absorbance peak at $1092 \mathrm{~cm}^{-1}$ in the infrared spectrum, likely due to asymmetrical stretching vibrations of $\mathrm{Si}-\mathrm{O}-\mathrm{Si}$, while the absorbance peaks at $798 \mathrm{~cm}^{-1}$ and $468 \mathrm{~cm}^{-1}$ likely indicate symmetrical stretching vibrations and bending vibrations of $\mathrm{Si}-\mathrm{O}-\mathrm{Si}$, respectively. These observations indicated the formation of a complex containing SiO2 and showed that the $\mathrm{Fe}_{3} \mathrm{O}_{4}$ on the surface was bound to $\mathrm{SiO}_{2}$, forming $\mathrm{SiO}_{2}-\mathrm{Fe}_{3} \mathrm{O}_{4}$. Lastly in Figure 3(c), the absorbance peaks at $1634 \mathrm{~cm}^{-1}$ and $3447 \mathrm{~cm}^{-1}$ likely represent the stretching vibration peaks of the carbonyl $(\mathrm{C}=0)$ bond and the carboxyl $(-\mathrm{COOH})$ bond, respectively, indicating the presence of monomeric methacrylate in the MMIPs.

Fig. 2 Infrared spectra of (a) $\mathrm{Fe}_{3} \mathrm{O}_{4}$, (b) $\mathrm{SiO}_{2}-\mathrm{Fe}_{3} \mathrm{O}_{4}$, and (c) MMIP.

Transmission electron microscopic (TEM) analysis of ofloxacin chiral MMIPs

TEM (JEM-2100) was used for examining the $\mathrm{SiO}_{2}-\mathrm{Fe}_{3} \mathrm{O}$, and MMIP at a magnification of $10,000-x$ and an accelerating voltage of $75 \mathrm{kV}$. As shown in Figure 3, the particle size distribution of SiO2-Fe304 was 
basically uniform, with particle sizes around $50 \mathrm{~nm}$ (Figure 3(a)). As shown in Figure 3(b), the particle size of MMIPwas around $100 \mathrm{~nm}$, indicating that $\mathrm{SiO}_{2}-\mathrm{Fe}_{3} \mathrm{O}_{4}$ acted as a carrier and that MIPs were synthesized by the binding of crosslinking agents and functional monomers on its surface, resulting in the increased particle size.

Fig. 3 TEM images of (a) $\mathrm{SiO}_{2}-\mathrm{Fe}_{3} \mathrm{O}_{4}$, and (b) MMIP.

\section{Determination of binding capacity of chiral MMIP}

The UV standard curve of ofloxacin was used to calculate the concentration of MMIP and MNIP before and after addition into the solvent. The binding rates of MMIP and MNIP to different concentrations of ofloxacin were calculated using formula (1). Figure 4 shows an isothermal graph of the binding rate of ofloxacin MMIPs. The binding capacity of MNIP was significantly lesser than that of MIPs; as the concentration of ofloxacin solution increased, the binding capacity of MMIPs also increased. When the concentration was $0.036 \mathrm{mg} / \mathrm{L}$, the binding capacity was gradually saturated, as evidenced by the binding curve. These observations indicated that the ofloxacin MMIPs prepared in the laboratory were capable of binding well to ofloxacin.

Fig. 4 Adsorption isotherm of ofloxacin for MMIP and MNIP.

\section{Experimental chromatogram}

A nearly parallel baseline was obtained when the baseline run was performed. As shown in Figure 5, peaks were observed at $0.6 \mathrm{~min}$, indicating the detection of (-)-ofloxacin. As the prepared MMIP could bind specifically to (+)-ofloxacin, (-)-ofloxacin would be eluted at $0.6 \mathrm{~min}$; thus, the eluent collected at 0.6 min would be (-)-ofloxacin.

Fig.5 Column chromatogram of (-)-ofloxacin

\section{Specific rotatory power of (-)-ofloxacin}

Similar to melting and boiling points, specific rotation is a physical constant for optically active substances. By determining the specific rotation of unknown substances, allows us to infer their identity. Determining the specific rotation of known substances allows us to calculate their optical purity. Thus, determining the specific rotation of optically active substances is one of the commonly used qualitative and quantitative methods.

The specific rotation ([a]t $\lambda$ ) can be calculated from the concentration of the tested substance (C) and the optical rotation (a) measured using the polarimeter, using the formula:

$$
[\alpha]_{2}^{t}=100 \alpha / l \times C
$$


where $t$ is the temperature at which the measurement was taken (generally $20{ }^{\circ} \mathrm{C}$ ), $\lambda$ is the wavelength of the light source (the commonly used sodium lamp has a wavelength of $589 \mathrm{~nm}$, and is represented by the symbol D), $a$ is the measured optical rotation $\left({ }^{\circ}\right), C$ is the concentration of the measured solution $(\mathrm{g} / 100$ $\mathrm{mL})$, and $\mathrm{I}$ is the length of the tube (dm).

The measured (-)-ofloxacin concentration was $C=0.1$, and the final specific rotation obtained was $a=-$ $65^{\circ}$. From these results, we concluded that the final solid obtained was (-)-ofloxacin.

\section{Discussion}

Ofloxacin is an important drug with anti-bacterial effects, and (-)-ofloxacin has been shown to have better anti-bacterial activity than racemic ofloxacin, and the bio-availability is close to $100 \%$. The separation of synthesized drugs has always been a challenge in the pharmaceutical industry. Therefore, developing effective, simple, and rapid resolution methods is a priority. The chiral reagent, N-n-Octyl-Dglucamine was used as monomers and magnetic nanoparticles were used as carriers to obtain chiral MMIPs. This method helped overcome the challenge of obtaining pure enantiomers for use as template molecules during chiral MIP preparation. Moreover, MIP technology can be used to overcome the challenge of binding and that of eluting template molecules and MIPs, as well as the low number of binding sites. Compared to other typical chiral separation methods, this method is advantageous in that it is rapid, simple, and inexpensive.

\section{Conclusion}

- In conclusion, a method for the rapid resolution of ofloxacin was established. The chiral MMIPs could specifically bind to (+)-ofloxacin molecules, enabling the separation of (-)-ofloxacin from racemic ofloxacin. The optical rotation and specific rotation of the obtained (-)-ofloxacin was measured in order to prove the feasibility of this method.

\section{Materials And Methods}

\section{Materials}

$\mathrm{FeCl}_{2} \cdot 4 \mathrm{H}_{2} \mathrm{O}_{2}, \mathrm{FeCl}_{3} \cdot 6 \mathrm{H}_{2} \mathrm{O}$, ammonia (20\%), ethylene glycol diglycidyl ether (EGDE), isopropanol, and tetraethyl orthosilicate (TEOS) were purchased from TCI Development Co., Ltd, Shanghai, China. Methanesulfonic acid (Chinese Medical Chemicals, Shanghai, China), triethoxyvinylsilane (TTS, SigmaAldrich, USA), N-n-Octyl-D-glucamine (Sigma-Aldrich, USA), and ammonium persulfate (Chinese Medical Chemicals, Shanghai, China) were of analytical grade.

\section{Methods}


Preparation of ofloxacin chiral MMIP

- Preparation of magnetic nanoparticles $\left(\mathrm{Fe}_{3} \mathrm{O}_{4}\right)$

$\mathrm{FeCl}_{2} \cdot 4 \mathrm{H}_{2} \mathrm{O}(1.72 \mathrm{~g}), \mathrm{FeCl}_{3} \cdot 6 \mathrm{H}_{2} \mathrm{O}(4.72 \mathrm{~g})$, and deionized water $(80 \mathrm{ml})$ were added to a flask with a continuous stream of nitrogen gas, and then heated and stirred using a magnetic stirrer. When the temperature had reached $80^{\circ} \mathrm{C}$, ammonia $(10 \mathrm{~mL})$ was slowly added and allowed to react for $30 \mathrm{~min}$; black precipitates were obtained. The product was washed 4-6 times with deionized water to remove unreacted substances and impurities; they were then dried to obtain $\mathrm{Fe}_{3} \mathrm{O}_{4}$ nanoparticles.

- Synthesis of $\mathrm{SiO}_{2}$-encapsulated magnetic nanoparticles $\left(\mathrm{SiO}_{2}-\mathrm{Fe}_{3} \mathrm{O}_{4}\right)$

Three hundred milligrams of the magnetic nanoparticles, deionized water $(4 \mathrm{~mL})$, and isopropanol $(50 \mathrm{~mL})$ were mixed and subjected to ultrasonic treatment for $15 \mathrm{~min}$. Ammonia $(5 \mathrm{~mL})$ and tetraethyl orthosilicate (TEOS) $\left(2 \mathrm{~mL}\right.$ ) were sequentially added and continuously stirred at $25^{\circ} \mathrm{C}$ for $12 \mathrm{~h}$ for reaction. After reaction, the product was washed 4-6 times with distilled water. The product was enriched under a magnetic field and then isolated and dried to obtain SiO2-encapsulated magnetic nanoparticles (SiO2-Fe304)

- Preparation of chiral MMIPs

Ten grams of the $\mathrm{SiO}_{2}-\mathrm{Fe}_{3} \mathrm{O}_{4}$ was soaked in methanesulfonic acid solution (wt \%: 50\%) for $24 \mathrm{~h}$, and then rinsed with acetone and distilled water, before drying to obtain activated particles. Triethoxyvinylsilane (TTS) $(30 \mathrm{~mL}), 20 \mathrm{~g}$ activated $\mathrm{SiO}_{2}-\mathrm{Fe}_{3} \mathrm{O}_{4}$ nanoparticles, and ethanol (ethanol: water $\left.=1: 1\right)(400 \mathrm{~mL}$ ) were added to a round-bottomed flask and allowed to react at $50{ }^{\circ} \mathrm{C}$ for $31 \mathrm{~h}$. The product was rinsed with ethanol and distilled water, and then dried to obtain TTS- $\mathrm{SiO}_{2}-\mathrm{Fe}_{3} \mathrm{O}_{4}$. TTS-SiO $2-\mathrm{Fe}_{3} \mathrm{O}_{4}(3 \mathrm{~g})$, N-n-Octyl-Dglucamine $(10 \mathrm{~g})$, distilled water $(200 \mathrm{~mL})$, and ammonium persulfate $(0.018 \mathrm{~g})$ were added to a roundbottomed flask and allowed to react at $70^{\circ} \mathrm{C}$ for $7 \mathrm{~h}$. The product thus obtained was washed with ethanol and distilled water, and then enriched under a magnetic field, isolated, and dried. This product was then dissolved with $4 \mathrm{mmol} / \mathrm{L}$ ofloxacin in chloroform solution $(100 \mathrm{~mL})$, and nitrogen gas was added for $5 \mathrm{~min}$. After agitation for $6 \mathrm{~h}$, the EGDE was added and the solution was mixed for $8 \mathrm{~h}$ at $50{ }^{\circ} \mathrm{C}$, and then eluted (elution solution, ethanol: methanol: water $=2: 7: 1, \mathrm{v} / \mathrm{v} / \mathrm{v}$ ). The product was enriched under a magnetic field. And the MMIPs were dried at $80^{\circ} \mathrm{C}$.

Magnetic non-imprinted polymers (MNIPs) were prepared in the same manner, with the exception that the target compound, ofloxacin, was not added.

Detection of the binding capacity of chiral MMIPs

A ofloxacin standard curve was first prepared. ofloxacin MMIPs $(0.05 \mathrm{~g})$ were then added to different concentrations of ofloxacin solution and agitated for $2 \mathrm{~h}$ to ensure binding between MMIPs and ofloxacin. The supernatant was removed from the mixture and UV spectrophotometry was used to detect 
the absorbance of the solution at $349 \mathrm{~nm}$. The concentration after reaction was calculated based on the standard curve, and the Q value was calculated based on formula (1):

$$
Q=\frac{V\left(c_{1}-c_{2}\right)}{m}
$$

where $\mathrm{c} 1$ is the initial ofloxacin concentration $(\mathrm{mg} / \mathrm{L})$; $\mathrm{c} 2$ is the equilibrium ofloxacin concentration $(\mathrm{mg} / \mathrm{L}) ; \mathrm{V}$ is the volume of ofloxacin $(\mathrm{L}), \mathrm{m}$ is the mass of MMIPs $(\mathrm{g})$, and $\mathrm{Q}$ is the unit mass of MMIP that was bound to ofloxacin at equilibrium.

The binding rate for NIPs was detected in a similar manner, with the exception that MNIPs were added to the ofloxacin solution.

Chromatographic separation and specific rotatory power of ofloxacin

- Chromatographic separation of ofloxacin

Half a gram of the sample and 8 times the sample weight of MMIPs were weighed $(4 \mathrm{~g})$. Ethyl acetate $(2 \mathrm{~mL})$ was added to the sample to form ofloxacin solution. Two volumes of solvent (ethyl acetate) was added to MMIPs and mixed with a glass stirrer; the mixture was left to stand for $24 \mathrm{~h}$, and a homogenous suspension was obtained after stirring. The column was then prepared for loading and loaded with this mixture. The prepared MMIP paste was injected uniformly into the column through a funnel while stirring. Twice the volume of the column of the remaining MMIPs was then added at a low flow rate. When the precipitation was complete, the device was clamped to iron pillars and prepared for the baseline run. After connecting the device, the baseline run was initiated and the chromatogram was obtained in $1 \mathrm{~h}$. In this experiment, the sample was wet-loaded. After the sample entered the column containing MMIPs, the elution solution was used for column elution at a flow rate of $3 \mathrm{~mL} / \mathrm{min}$. The collection device was used to collect the eluent for UV spectroscopy.

- Specific rotatory power of ofloxacin

The polarimeter was pre-warmed for $30 \mathrm{~min}$ and zeroed using the blank solvent. The test sample was accurately weighed and adjusted to a fixed concentration using a volumetric flask. It was then sealed before insertion into the polarimeter for determining its specific rotatory power.

\section{Abbreviations}

\section{TEM}

transmission electron microscopy

GC

gas chromatography 
HPLC

high performance liquid chromatography

CE

capillary electrophoresis

MMIPs

magnetic molecularly imprinted polymers

MNIPs

magnetic non-imprinted polymers

MIPs

molecularly imprinted polymers

EGDE

ethylene glycol diglycidyl ether

TEOS

tetraethyl orthosilicate

TTS

triethoxyvinylsilane

\section{Declarations}

\section{Availability of data and material}

The data sets used and/or analyzed during the current study are available from the corresponding author on reasonable request.

\section{Acknowledgements}

The authors are grateful to all the study participants.

\section{Funding}

This work was supported by the Natural Science Foundation Research Project of Shaanxi Province of China (2018JQ2075, and 2014JQ2-8053) and National students innovation and entrepreneurship training (201610702017). The funding agency had no role in the study design; the collection, analysis, and interpretation of data; the writing of the report; or the decision to submit the article for publication.

\section{Authors information}

\section{Affiliation}

School of Electronic and Information Engineering of Xi'an Technological University,Xi'an City, Shanxi Province, 710021, Peoples Republic of China

Chen Zhao, Wenzong Lu, Mengxiang Yang 


\section{Contributions}

All authors have read and agree to the published version of the manuscript. Conceptualization, Chen Zhao; methodology, Xiangyang Meng; formal analysis, Wengzong Lu; writing-original draft preparation, Chen Zhao; writing-review and editing

\section{Corresponding Author}

Correspondence to Chen Zhao

Ethics approval and consent to participate:Not applicable

Consent for publication $\square$ Not applicable

Competing interests $\mathbb{X}$ The authors declare no conflicts of interest.

\section{References}

1. Fu KP, Lafredo SC, Foleno B. et al. In vitro and in vivo antibacterial activities of levofloxacin (Iofloxacin), an optically active ofloxacin.[J]. Antimicrob Agents Chemother. 1992;36(4):860-6.

2. Al-Jabari MH, Sulaiman S, Ali S. et al. Adsorption study of levofloxacin on reusable magnetic nanoparticles: Kinetics and antibacterial activity[J]. J Mol Liq. 2019;291:111249.

3. Natalia Wrońska, Majoral JP, Appelhans D. et al. Synergistic Effects of Anionic/Cationic Dendrimers and Levofloxacin on Antibacterial Activities[J]. Molecules. 2019;24(16):2894.

4. Shiwang LIU, Yangxia XU, Guliang YANG. Study on separating ofloxacin by the chiral selector [J]. Journal of Huanggang normal university. 2007;19(6):12-5.

5. Naici BING, Zhengliang XU, Xuejun WANG. et al. Levofloxacin-Imprinted membranes for selective separation of ofloxacin under solid phase extraction conditions[J]. Journal of east china university of science technology: natural science edition. 2007;26(1):78 - 74 .

6. Wei JA, Mohr S, Schmid MG. Indirect chiral separation of new recreational drugs by gas chromatography-mass spectrometry using trifluoroacetyl-L-prolyl chloride as chiral derivatization reagent.[J]. Chirality. 2015;27(3):211-5.

7. Tian M, Row HS, Row KH. Chiral separation of ofloxacin enantiomers by ligand exchange chromatography[J]. Monatshefte für Chemie - Chemical Monthly. 2010;141(3):285-90.

8. Zhili F, Ziyuan G, Qing Q., et al. Semi-Preparative Enantiomeric Separation of Ofloxacin by HPLC[J]. Journal of Chromatographic ence, 2013, (2):133-137.

9. Zi-Fu XU, Jin G, Shuang S, et al. Determination of ofloxacin enantiomers by CE method using a dual chiral selectors system[J]. Chinese Journal of Analysis Laboratory, 2019.

10. Wang F, Khaledi MG. Capillary electrophoresis chiral separation of basic pharmaceutical enantiomers with different charges using sulfated $\beta$-cyclodextrin[J]. J Microcolumn Sep. 2015;11(1):11-21. 
11. Chakraborty S, Razonabe CC, Chua MT. Nanoparticulate molecularly imprinted poly(acrylic acid) as potential stationary phase for chiral separation of ofloxacin[J]. International Journal of Nano Biomaterials. 2014;5(2/3):152.

12. Yong LI, Huanghao YANG, Zhixia ZHUANG, et al. Surface Molecularly Imprinted Polymer Nanowires Used for Protein Recognition [J]. Chemical journal of Chinese universities. 2005;26(9):1634-6.

13. Zhao C, Jia GF, Lu WZ, et al. A piezoelectric magnetic molecularly imprinted surface sensor for the detection of Sudan I. J Chromatogr A. 2017;1216:3710-9.

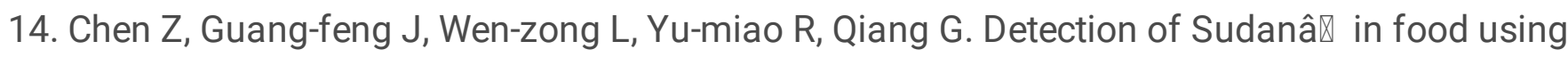
magnetic molecularly imprinted polymer microspheres. Mod Food SciTech. 2016;32:302-7.

15. Weihai YANG, Yao WU, Tie ZHANG, et al. Preparation and Application of Core-Shell Magnetic Molecularly Imprinted Polymer Microspheres [J]. Progress in chemistry. 2010;22(9):1819-25.

16. Chen LG, Zeng LJ. Q L. Preparation of magnetic molecularly imprinted polymer for the separation of tetracycline antibiotics from egg and tissue samples[ J]. J Chromatogr A. 2009;1216:3710-9.

17. Li L, He XW, Chen LXJ. Preparation of core-shell magneticmol ecularly imprinted polymer nanoparticles for recognition of Bovine $\mathrm{H}$ emoglobin[J]. Chem Asian. 2009;4:286-93.

18. Xiaoyan GONG, Xuejun CAO. Preparation of Molecularly Imprinted Polymers for Aitemisinin Based on the Surfaces of Silica Gel [J]. J Biotechnology. 2011;153(1/2):8-14.

19. Chen Z, Dao-cheng W. Rapid detection assay for the molecular imprinting of gossypol using a twolayer PMAA $/ \mathrm{SiO}_{2}$ bulk structure with a piezoelectric imprinting sensor. Sen Act: B Chemical. 2013;181:104-13.

20. Chen Z, Yu-miao R, Wen-zong L, Meng-jie Z. Detection of Piezoelectric Magnetic Surface Molecularly Imprinted Sensor to Chloramphenicol. Sci Tech Eng. 2016;16:149-53.

\section{Figures}

a

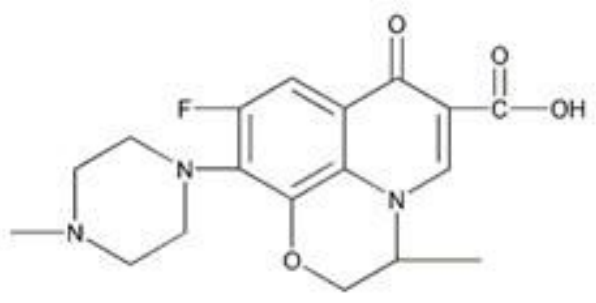

b

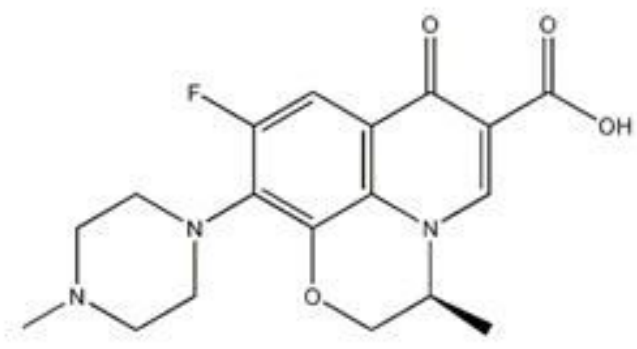

\section{Figure 1}

Structures of (a)(+)-ofloxacin and (b) (-)-ofloxacin 


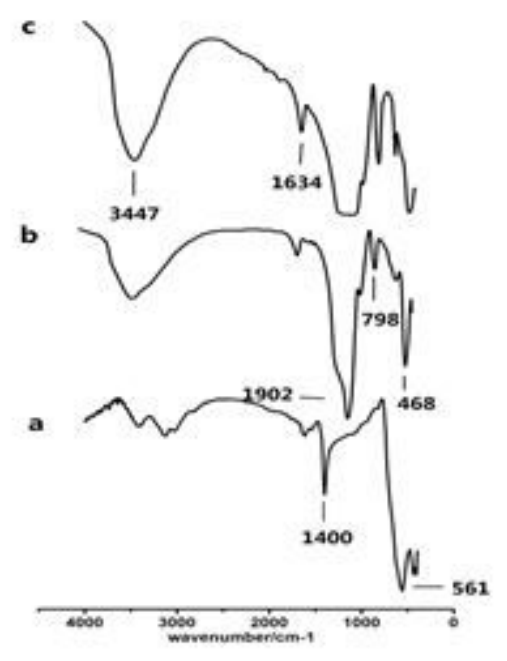

Figure 2

Infrared spectra of (a) Fe304, (b) SiO2-Fe304, and (c) MMIP.

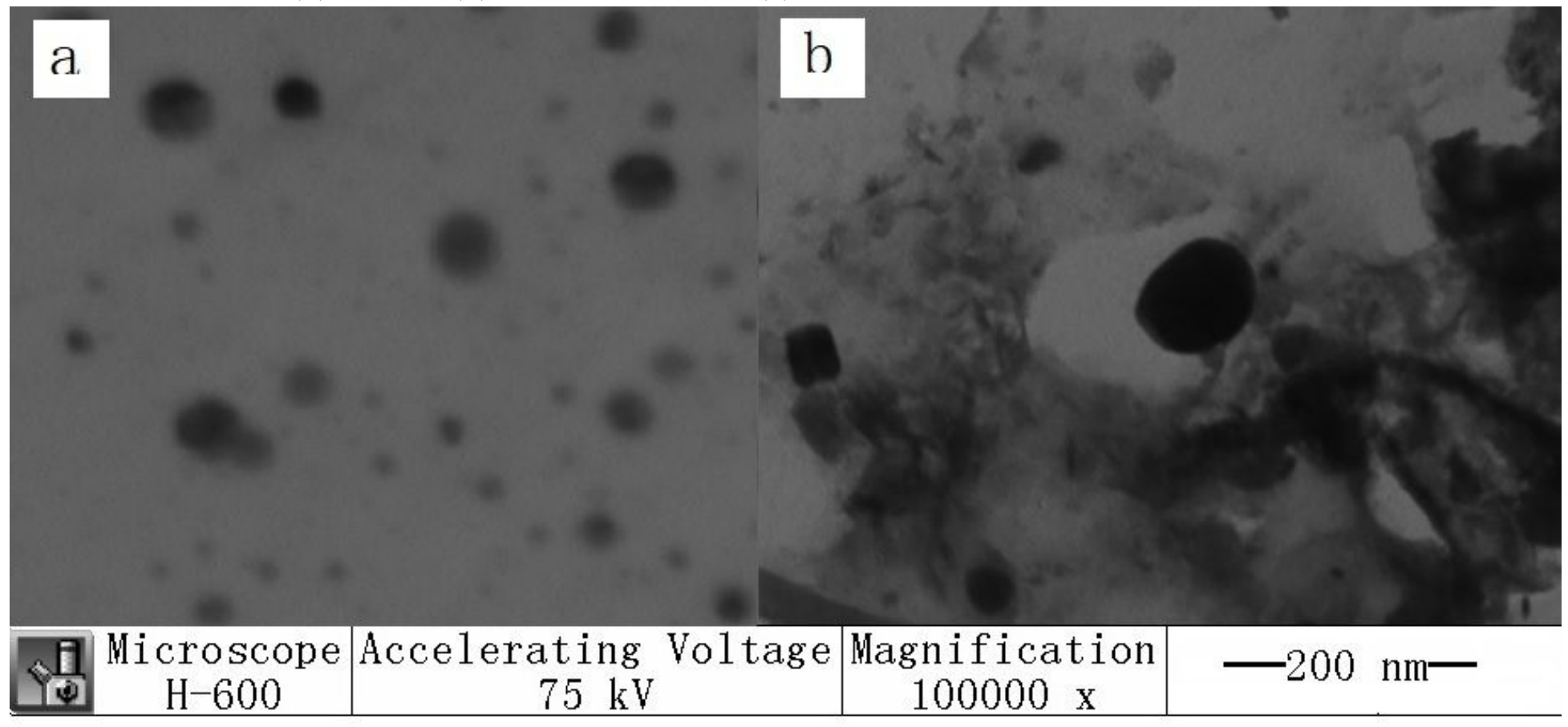

\section{Figure 3}

TEM images of $\neg$ (a) SiO2-Fe304, and (b) MMIP. 


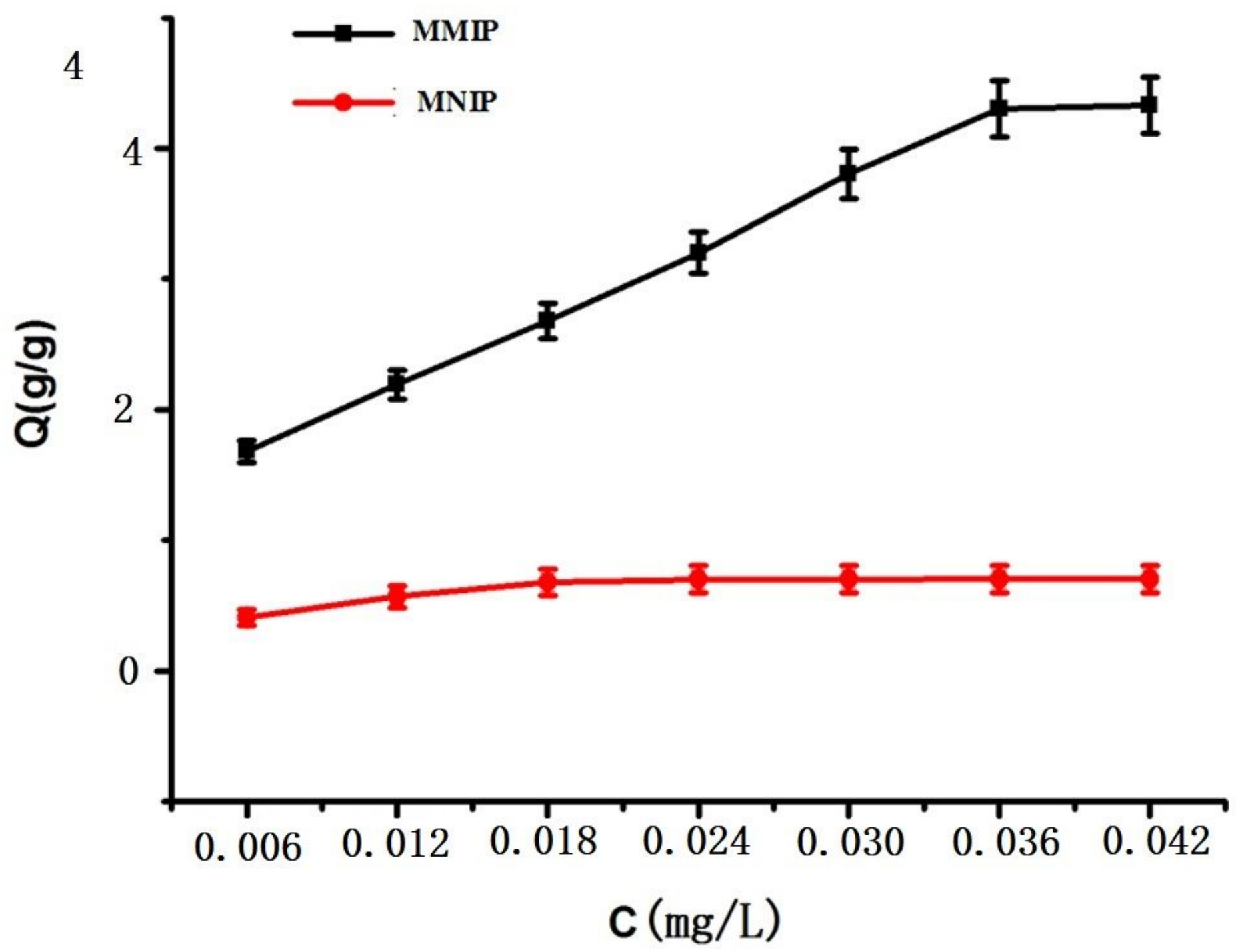

Figure 4

Adsorption isotherm of ofloxacin for MMIP and MNIP. 


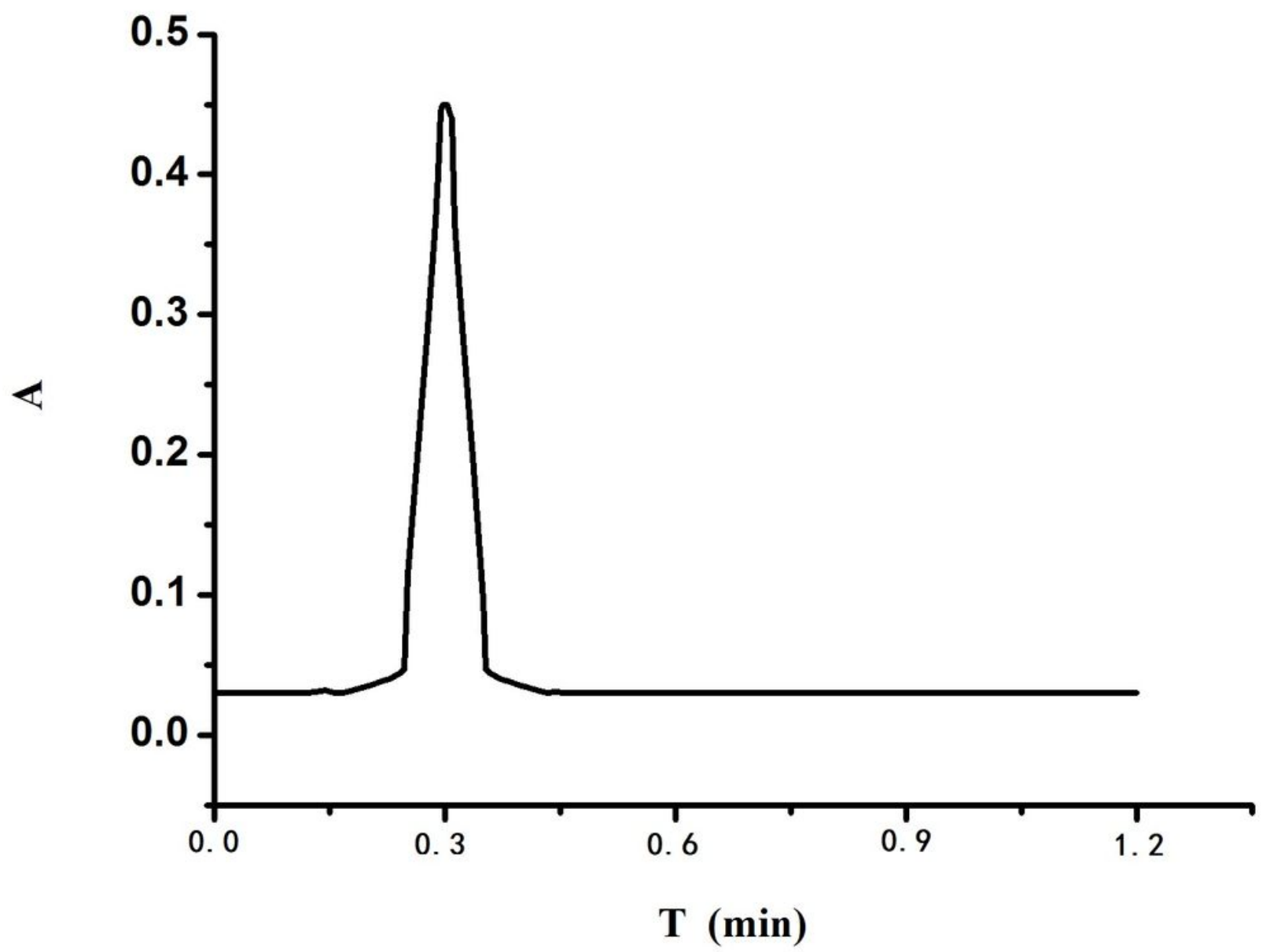

Figure 5

Column chromatogram of (-)-ofloxacin 